ORIGINAL ARTICLE

AFRICAN JOURNAL OF CLINICAL AND EXPERIMENTAL MICROBIOLOGY SEPTEMBER 2013 ISBN 1595-689X VOL14 No.3

AJCEM/1322

COPYRIGHT 2013

http://www.ajol.info/journals/ajcem

AFR. J. CLN. EXPER. MICROBIOL. 14(3): 174-179. http:/ / dx.doi.org/10.4314/ajcem.v14i3.10

\title{
KNOWLEDGE, ATTITUDE AND PRACTICE OF BLOOD CULTURE: A CROSS SECTIONAL STUDY AMONG MEDICAL DOCTORS IN A NIGERIAN TERTIARY HOSPITAL.
}

\author{
OJIDE, C. K. , ONWUEZOBE, I. A., ASUQUO, E. E., OBIAGWU, C. S.
}

Department of Medical Microbiology and Parasitology, UUTH, Uyo, Akwa-Ibom.

*Correspondence: Dr Ojide, Chiedozie Kingsley, Department of Medical Microbiology and Parasitology, University of Uyo Teaching Hospital, Uyo, Akwa-Ibom State, Nigeria. E-mail: edomann2001@yahoo.com. Phone No: +2348052534844

\begin{abstract}
Background: Blood culture is one of the most important investigations done in clinical microbiology laboratories. Not only has it been long recognized as the "gold standard" for diagnosis of Blood Stream Infections (BSIs), very important decisions regarding septicaemic patients' management are based on it. Being a user-dependent diagnostic test, quality of results often depends on the performer.

Aim: To study the knowledge, attitude and practice of blood culture among doctors in a Nigerian tertiary hospital.

Materials and Methods: A pre-tested self-administered semi- structured questionnaire developed by the research team was used to access the biodata, knowledge, attitude and practice of blood culture among doctors in our institution.

Results: Forty-eight $(54.5 \%)$ out of the 88 doctors studied had good knowledge regarding blood culture, $34(38.6 \%)$ moderate knowledge and $6(6.8 \%)$ poor knowledge. Majority of the senior registrars $(75.0 \%)$, registrars $(64.3 \%)$ and house officers $(65.9 \%)$ studied had good knowledge while majority of the consultants $(75.0 \%)$ had moderate knowledge. Doctors from paediatrics $(62.5 \%)$ and internal medicine $(60.0 \%)$ departments had higher proportions with good knowledge compared to those from surgery $(57.9 \%)$ and obstetrics and gynaecology $(45.0 \%)(p=0.240)$. Majority of the doctors with $<10$ years experience as doctors $(57.0 \%)$ had good knowledge compared to $33.3 \%$ recorded among those $\geq 10$ years. Attitude and practice was generally positive.

Conclusion: Through this study areas of unsatisfactory knowledge, attitude and practice of blood culture were identified. This will help in designing an educational intervention programme for the purpose of addressing identified problems areas in blood culture.
\end{abstract}

KEYWORDS: Blood culture, Knowledge, Attitude, Practice, Doctors.

\section{INTRODUCTION}

Blood culture is one of the most important investigations done in clinical microbiology laboratories. It has long been recognized as the "gold standard" for diagnosis of Blood Stream Infections (BSIs) which accounts for $10 \%$ of all nosocomial infection with mortality approaching $15 \%$ [1]. Not only will blood culture help in the isolation of offending pathogens, it also allows susceptibility tests to be carried out on isolates. Thus very important decisions regarding the choice of antibiotics for managing patients with BSI are based on blood culture results. It is therefore very crucial that the test must be done with best practices.

Evidence has shown that this very important test is often sub-optimally done. According to American Society of Microbiology, the rate of contaminants of blood cultures should not exceed 3\% [2]. However, the baseline contamination rates of many institutions in the developed countries are often higher than this rate [3] [4] [5]. The situation in developing countries like Nigeria may even be worse. The consequences of increased contamination rate of blood culture are grave. Hospital bill are usually increased while clinicians are confused, especially when there is discordance between results and clinical features [2] [6].

Being a highly user-dependent diagnostic test, the quality of blood culture results does not only depend on the nature of the underlying infectious process but more importantly on the performer [7]. For example when aseptic procedures during specimen collection are strictly adhered to, there were significant reductions in contamination rates [8] [9]. Also correct timing of sampling in relation to fever and antibiotics administration; and sampling of adequate volume of blood are other userdependent factors that affect yield [7] [8] [9]. Whereas the level of knowledge, training and years of experience of medical personnel impacts so much on resource utilization and diagnostic test use [7] [10], there is a dearth of information on the knowledge, attitude and practice of blood culture among doctors. This study was therefore aimed at studying the knowledge, attitude and practice of blood culture among medical doctors in our institution.

\section{METHODOLOGY}

This descriptive cross-sectional study was carried out among doctors working at the University of 
Uyo Teaching Hospital, a tertiary institution located at the south-south region of Nigeria.

A pre-tested self-administered semi- structured questionnaire developed by the research team was used to access the biodata, knowledge, attitude and practice of blood culture among doctors in our institution. The study population comprised of different cadres of doctor viz: house officers, registrars, senior registrars and consultants, from different departments including internal medicine, paediatrics, surgery, obstetrics and gynaecology and others.

Verbal consents were sought and obtained from the different heads of departments and the doctors themselves, and each consenting doctor was handed the questionnaire to complete. The mean time for completing the questionnaire was 10 minutes. Confidentiality was assured and strictly maintained. Completed questionnaires were collected by the investigators and data obtained were analyzed using the Statistical Package for Social Sciences (SPSS) version 17.

The questionnaire comprised of three sections viz; sociodemographic, knowledge assessment (comprising of seven questions) and attitude and knowledge (comprising of seven questions) sections. The seven questions used to access level knowledge of blood culture covered what a set of blood culture comprised, the number of sets required in standard blood culture, nature of organisms supported by a blood culture set, temperature at which blood cultures are incubated, the necessity of strict asepsis during sampling and the effect of prior antibiotics use and volume of blood sampled on recovery of organisms. Correct answer for each question was scored 2 and incorrect or unsure answers were scored zero. Total scores of 0-4, 5-9 and 10-14 were categorized as poor, moderate and good knowledge. Fisher's exact or Chi square, where appropriate, was used to assess associations between level of knowledge and sociodemographic variables. Significant association was presumed at $\mathrm{p}$ value less than 0.05

\section{RESULTS}

A total of 88 doctors took part in the study comprising of $56(63.6 \%)$ males and $32(36.4 \%)$ females. Majority of the doctors studied (58.0\%) were in the age bracket $20-29$ years, followed by $30-$ 39 years age bracket $(27.3 \%)$; age bracket $\geq 50$ years had only one representation $(1.1 \%)$ as shown in Table 1. More than half of the doctors studied $(54.5 \%)$ were house officers, $28(31.8 \%)$ registrars, 8 $(9.1 \%)$ consultants, and $4(4.5 \%)$ senior registrars (Table 1).
Of the 88 doctors studied, $24(27.3 \%)$ were from paediatrics department, 20 (22.7\%) each from internal medicine and obstetrics/gynaecology respectively, $19(21.6 \%)$ from surgery and $5(5.7 \%)$ from others departments (Haematology $\{x 2\}$, Family Medicine, Clinical Chemistry, and Psychiatry). Majority of the doctors studied $(89.7 \%)$ had practiced for less than 10 years (Table 1 ).

Regarding the individual questions assessing knowledge of blood culture, more than half of those that responded $(57.6 \%)$ knew that a set of blood culture comprises of two blood culture bottles, $80.5 \%$ were aware that a set of blood culture should support the growth of both aerobic and anaerobic organisms while $57.5 \%$ knew that standard blood culture should comprise of 2-3 sets of blood culture bottles (Table 2).

TABLE 1: SOCIO-DEMOGRAPHIC CHARACTERISTICS OF DOCTORS STUDIED.

\begin{tabular}{lll}
\hline Characteristics & Number & Percent (\%) \\
\hline Gender & 56 & 63.6 \\
Male & 32 & 36.4 \\
Female & & \\
Age groups (years) & 6 & 6.8 \\
$<20$ & 51 & 58.0 \\
$20-29$ & 24 & 27.3 \\
$30-39$ & 6 & 6.8 \\
$40-49$ & 1 & 1.1 \\
$\geq 50$ & & \\
Rank & 48 & 54.5 \\
House officer & 28 & 31.8 \\
Registrar & 4 & 4.5 \\
Senior registrar & 8 & 9.1 \\
Consultant & & \\
Department & 24 & 27.3 \\
Paediatrics & 20 & 22.7 \\
Internal Medicine & 22.7 \\
Obstetrics/Gynaecology & 20 & 21.6 \\
Surgery & 19 & 5.7 \\
Others & 5 & \\
Years of Experience & & \\
(years) & & \\
$<10$ & 79 & \\
$\geq 10$ & 9 & \\
\hline & & \\
& &
\end{tabular}




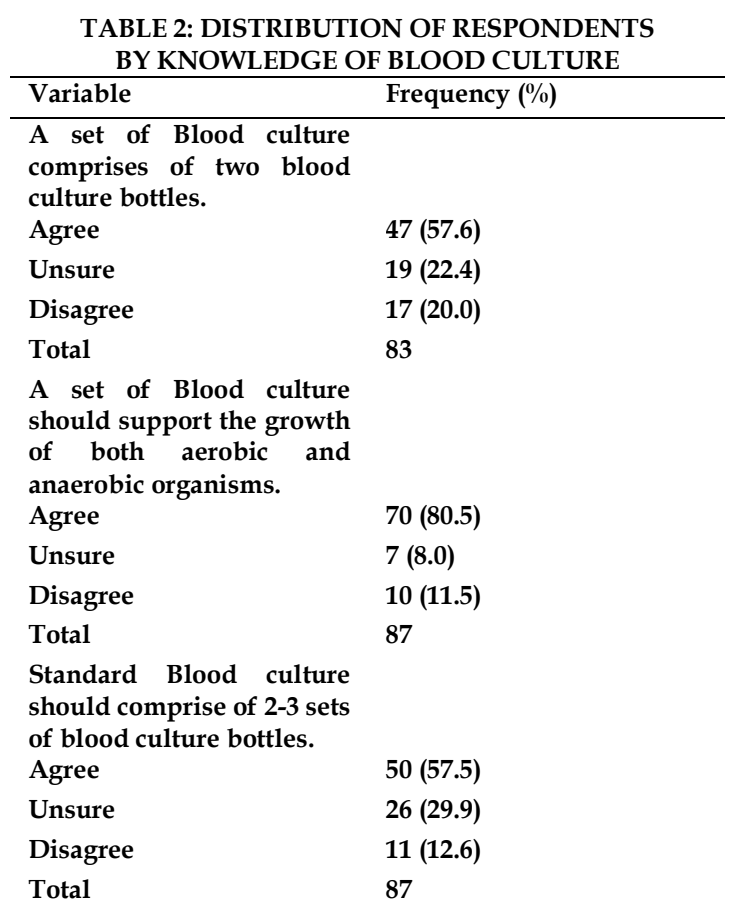

\begin{tabular}{|c|c|}
\hline \multirow{2}{*}{$\begin{array}{l}\text { Variable } \\
\text { Blood cultures are usually } \\
\text { incubated at } 37^{\circ} \mathrm{C} \text {. }\end{array}$} & Frequenc \\
\hline & \\
\hline Agree & $33(37.9)$ \\
\hline Unsure & $22(25.3)$ \\
\hline Disagree & $32(36.7)$ \\
\hline Total & 87 \\
\hline $\begin{array}{l}\text { Strict asepsis is necessary } \\
\text { during sampling. } \\
\text { Agree }\end{array}$ & $72(83.7)$ \\
\hline Unsure & $12(14.0)$ \\
\hline Disagree & $2(2.3)$ \\
\hline Total & 86 \\
\hline $\begin{array}{l}\begin{array}{l}\text { Antibiotics use } \\
\text { sampling } \\
\text { organisms yield. }\end{array} \\
\text { affects }\end{array}$ & \\
\hline Agree & 85 (96.6) \\
\hline Unsure & $0(0.0)$ \\
\hline Disagree & $3(3.4)$ \\
\hline Total & 88 \\
\hline $\begin{array}{l}\text { Volume of blood sampled } \\
\text { affects quality of result. } \\
\text { Agree }\end{array}$ & $24(28.6)$ \\
\hline Unsure & $42(50.0)$ \\
\hline Disagree & $18(21.4)$ \\
\hline Total & 84 \\
\hline
\end{tabular}

consultants $(75.0 \%)$ had moderate knowledge (Table 4).

Further analysis of data showed that $48(54.5 \%)$ out of the 88 doctors studied had good knowledge regarding blood culture, $34(38.6 \%)$ moderate knowledge and $6(6.8 \%)$ poor knowledge (Table 3$)$. The proportion of female that had good knowledge $(56.3 \%)$ was slightly more than the males $(53.6 \%)$ ( $p$ $=0.967$ ) as shown in Table 4. Furthermore good knowledge did not vary in any particular direction with age. Majority of the senior registrars $(75.0 \%)$, registrars (64.3\%) and house officers (65.9\%) studied had good knowledge while majority of the
Blood cult

$(86$

$85(96.6)$

$(0.0)$

$(3.4)$

$4(28.6)$

$18(21.4)$

TABLE 4: ASSOCIATION OF DEMOGRAPHIC CHARACTERISTICS WITH LEVEL OF KNOWLEDGE

\begin{tabular}{|c|c|c|c|c|}
\hline \multirow[t]{2}{*}{ Characteristics } & \multicolumn{3}{|c|}{ Level of Knowledge } & \multirow{2}{*}{$\begin{array}{l}\mathrm{P} \text { value }\left(\chi^{2} \text { test/ Fisher }\right. \\
\text { Exact test })\end{array}$} \\
\hline & Poor (0-4) & Moderate (5-9) & Good (10-14) & \\
\hline \multicolumn{5}{|l|}{ Gender } \\
\hline Male & 4 (7.1) & $22(39.3)$ & $30(53.6)$ & 0.967 \\
\hline Female & $2(6.3)$ & $12(37.5)$ & $18(56.3)$ & \\
\hline \multicolumn{5}{|l|}{ Age group (yrs) } \\
\hline$<20$ & $0(0.0)$ & $3(50.0)$ & $3(50.0)$ & \\
\hline $20-29$ & $4(7.8)$ & $19(37.3)$ & $28(54.9)$ & \\
\hline $30-39$ & $2(8.3)$ & $7(29.2)$ & $15(62.5)$ & 0.477 \\
\hline $40-49$ & $0(0.0)$ & $5(83.3)$ & 1 (16.7) & \\
\hline$\geq 50$ & $0(0.0)$ & $0(0.0)$ & $1(100.0)$ & \\
\hline \multicolumn{5}{|l|}{ Rank } \\
\hline House officer & $4(10.5)$ & $9(23.7)$ & 25 (65.9) & \\
\hline Registrar & $1(3.8)$ & $9(32.1)$ & $18(64.3)$ & 0.135 \\
\hline Senior Registrar & $1(25.0)$ & $0(0.0)$ & $3(75.0)$ & \\
\hline Consultant & $0(0.0)$ & $6(75.0)$ & $2(25.0)$ & \\
\hline \multicolumn{5}{|l|}{ Department } \\
\hline Surgery & $1(5.3)$ & $7(36.8)$ & $11(57.9)$ & \\
\hline Internal Medicine & $0(0.0)$ & $8(40.0)$ & $12(60.0)$ & \\
\hline Paediatrics & $1(4.2)$ & $8(33.3)$ & $15(62.5)$ & 0.240 \\
\hline Obs \& Gynae & $4(20.0)$ & $7(35.0)$ & $9(45.0)$ & \\
\hline Others & $0(0.0)$ & $4(80.0)$ & $1(20.0)$ & \\
\hline \multicolumn{5}{|l|}{ Years of Experience } \\
\hline$<10$ years & $6(7.6)$ & $28(35.4)$ & $45(57.0)$ & 0.900 \\
\hline$\geq 10$ years & $0(0.0)$ & $6(66.7)$ & $3(33.3)$ & \\
\hline
\end{tabular}


Greater proportions of doctors from paediatrics $(62.5 \%)$ and internal medicine $(60.0 \%)$ departments had good knowledge compared to their counterparts from surgery $(57.9 \%)$ and obstetrics and gynaecology $(45.0 \%)(p=0.240)$. Majority of the doctors with $<10$ years experience as doctors $(57.0 \%)$ had good knowledge as against $33.3 \%$ recorded among those $\geq 10$ years (Table 4 ).

Regarding attitude and practice of blood culture, while $95.5 \%$ of respondents agreed that they sometimes make diagnosis requiring blood culture,

\begin{tabular}{|c|c|}
\hline Variable & Frequency (\%) \\
\hline $\begin{array}{l}\text { I sometimes make } \\
\text { diagnosis requiring blood } \\
\text { culture }\end{array}$ & \\
\hline Agree & $84(95.5)$ \\
\hline Unsure & $1(1.1)$ \\
\hline Disagree & $3(3.4)$ \\
\hline Total & 88 \\
\hline $\begin{array}{l}\text { I always request for blood } \\
\text { culture each time I make } \\
\text { diagnosis requiring it. } \\
\text { Agree }\end{array}$ & $33(39.8)$ \\
\hline Unsure & $0(0.0)$ \\
\hline Disagree & $50(60.2)$ \\
\hline Total & 83 \\
\hline $\begin{array}{l}\text { If patient is already on } \\
\text { antibiotics, I still request } \\
\text { for blood culture if } \\
\text { indicated } \\
\text { Agree }\end{array}$ & $58(66.7)$ \\
\hline Unsure & $6(6.9)$ \\
\hline Disagree & $23(26.4)$ \\
\hline $\begin{array}{l}\text { Total } \\
\text { I do deliver the blood } \\
\text { sample collected into the } \\
\text { culture bottle with the } \\
\text { same needle used for } \\
\text { venipuncture rather than } \\
\text { changing it. }\end{array}$ & 87 \\
\hline \multicolumn{2}{|c|}{$\begin{array}{c}\text { TABLE 6: REASONS GIVEN FOR NOT ALWAYS } \\
\text { REQUESTING FOR BLOOD CULTURE WHEN } \\
\text { REQUIRED }(\mathrm{N}=20) .\end{array}$} \\
\hline Reasons & Frequency (\%) \\
\hline Delay in getting results & $6(30.0 \%)$ \\
\hline $\begin{array}{l}\text { Blood culture bottles not } \\
\text { readily available }\end{array}$ & $5(25.0 \%)$ \\
\hline $\begin{array}{l}\text { Cost consideration for the } \\
\text { patients }\end{array}$ & $5(25.0 \%)$ \\
\hline $\begin{array}{l}\text { Results often not } \\
\text { convincing }\end{array}$ & $2(10.0 \%)$ \\
\hline $\begin{array}{lll}\text { Patients } & \text { already } & \text { on } \\
\text { antibiotics } & & \end{array}$ & $1(5.0 \%)$ \\
\hline $\begin{array}{l}\text { Not a requirement for } \\
\text { treating every case }\end{array}$ & $1(5.0 \%)$ \\
\hline
\end{tabular}

only $39.8 \%$ of those studied always request for the test when such diagnosis is made (Table 5). Twothird of the respondents $(66.7 \%)$ still request for blood culture if required when patient is already on antibiotics while $26.4 \%$ will not in a similar situation. Majority (82.4\%) agreed that drawing blood for routine culture from an intravenous catheter was a wrong practice; only $18.4 \%$ practiced single needle technique during sampling against $79.3 \%$ that practiced double needle technique (Table $5)$.

\begin{tabular}{|c|c|}
\hline Agree & $16(18.4)$ \\
\hline Unsure & $2(2.3)$ \\
\hline Disagree & $69(79.3)$ \\
\hline Total & 87 \\
\hline \multicolumn{2}{|c|}{$\begin{array}{l}\text { It is wrong practice to take } \\
\text { blood samples from } \\
\text { intravenous catheters for } \\
\text { routine blood culture }\end{array}$} \\
\hline Agree & $70(82.4)$ \\
\hline Unsure & $13(15.3)$ \\
\hline Disagree & $2(2.3)$ \\
\hline Total & 85 \\
\hline $\begin{array}{l}\text { Methylat } \\
\text { proposed } \\
\text { site is } \\
\text { preparati } \\
\text { sampling }\end{array}$ & \\
\hline Agree & $53(62.4)$ \\
\hline Unsure & 9 (10.6) \\
\hline Disagree & $23(27.1)$ \\
\hline Total & 85 \\
\hline $\begin{array}{l}\text { Am sati } \\
\text { results I } \\
\text { cultures }\end{array}$ & \\
\hline Agree & $24(31.2)$ \\
\hline Unsure & $16(20.8)$ \\
\hline Disagree & 37 (47.1) \\
\hline Total & 87 \\
\hline
\end{tabular}

TABLE 7: REASONS GIVEN FOR THINKING BLOOD CULTURE RESULTS ARE NOT SATISFACTORY (N =

\begin{tabular}{|c|c|}
\hline \multicolumn{2}{|c|}{ 17). } \\
\hline Reasons & Frequency (\%) \\
\hline Results usually delayed & $6(35.3)$ \\
\hline Results often negative & $4(23.5)$ \\
\hline $\begin{array}{ll}\text { Always } & \text { growing } \\
\text { Staphylococcus } & \end{array}$ & 3 (17.6) \\
\hline Don't isolate anaerobes & 2 (11.8) \\
\hline $\begin{array}{l}\text { Results often not agreeing } \\
\text { with clinical signs }\end{array}$ & $1(5.9)$ \\
\hline $\begin{array}{l}\text { Most patients on } \\
\text { antibiotics prior to culture }\end{array}$ & $1(5.9)$ \\
\hline
\end{tabular}


Table 6 shows the reasons why doctors studied do not always request for blood culture when they make diagnosis requiring it. "Delay in getting results" was the main reason $(6 / 20 ; 33.3 \%)$, followed by "blood culture bottles not readily available" and "cost consideration for the patients", each accounting for $25.0 \%$ of reasons given. Out of the 17 respondents that gave reasons why they thinks blood culture results were not satisfactory, 6 $(35.3 \%)$ felt "delay in getting result" was their problem, $4(23.5 \%)$ felt result were often negative, while $3(17.6 \%)$ felt blood cultures are always growing staphylococcus (Table 7).

\section{DISCUSSION}

There are limited studies on knowledge, attitude and practice of doctors on blood culture among medical doctors. Doctors are the ones that request for blood cultures and in most hospitals, especially tertiary institutions, are responsible for sampling for blood culture and transporting same to the laboratories for incubation and further processing. Therefore by virtue of training and practice they are expected to have good knowledge of blood culture. In this study $54.5 \%$ of the doctors studied demonstrated good knowledge of blood culture.

There are however specific areas of knowledge regarding blood culture that lower than expected performance was recorded. Regarding the temperature at which blood cultures are incubated, for instant, only $37.9 \%$ of doctors studied agreed that $37{ }^{\circ} \mathrm{C}$ was the temperature for incubation, $25.3 \%$ were unsure while $36.7 \%$ disagreed. Perhaps the reason for the lower performance on this question is that most doctors, apart from the laboratory physicians, do not have sufficient knowledge of the happenings in the laboratory. As soon as specimens are submitted at the receptions of the laboratories they are done and only wait for the results. It is advocated that all doctors are made to rotate through the laboratories to acquaint themselves with how specimens are further processed beyond reception, as experience garnered during undergraduate laboratory posting appears not to be sufficient.

Another specific area where level of knowledge was below expectation in this study was regarding volume of blood sampled affecting quality of result as only $28.6 \%$ agreed that volume of blood sampled affects quality of result; the rest either disagreed or were not sure. Volume of blood per culture has always been known as the single most important variable affecting recovery of microorganisms from patients with sepsis. Several studies have confirmed that the higher the volume cultured, the higher the rate of detection of bloodstream infection, reporting increase in yield from $0.6-4.7 \%$ per extra $\mathrm{ml}$ of blood cultured [11] [12]. Inadequate volume of blood is a common problem observed during blood culture sampling. Connell et al, in their study reported that only $46.0 \%$ of blood from infants and children submitted for culture in their centre had adequate volume of blood [13]. However after an educational intervention, there was a significant increase in the proportion of adequate volume of blood collected to $63.9 \%$ [13]. Similar educational intervention might be necessary in the study area to bridge the gap in knowledge thus improving the quality of blood culture result.

This study equally revealed that while greater proportion of senior registrars, registrars and house officers had good knowledge of blood cultures, majority of the consultants had moderate knowledge. The reason for this disparity is not known but may be connected to the fact that residents and house officers are more practically involved in blood cultures than the consultants. Patients from paediatrics and internal medicine wards often present with septicaemia more than those in surgery and obstetrics/gynaecology wards [14], thus doctors from paediatrics and internal medicine departments would more than their counterparts from other specialties request for and be more conversant with blood culture. It therefore follows that level of knowledge of blood culture among doctors from paediatrics and internal medicine, as found in this study, is expected to be higher than other specialties.

The attitude and practice of blood culture from this study was generally positive. It is of note that whereas $95.5 \%$ of the doctors studied sometimes make diagnosis requiring blood culture, only $39.8 \%$ always request for the test whenever such diagnosis is made. This figure is considerably low. Out of the $50(60.2 \%)$ doctors that did not always request for blood cultures when indicated only 20 (40.0\%) indicated why, with the most common reason given being "delay in getting results" $(30.0 \%)$. Timeliness of results reporting has been a major concern in most clinical laboratories due to increasing pressure from clinicians to report results rapidly. Even though there are only sparse data, timeliness in reporting of laboratory results undoubtedly affects clinician and patient satisfaction as well as length of hospital stay [16]. Improving turnaround time (TAT) is a complex task involving education, equipment acquisition, and planning [15]. Other common reasons given are "unavailability of the blood culture bottle" (25.0\%) when needed, a peculiar problem in the study area requiring attention, and "cost consideration for the patients" (25.0\%), an important factor affecting utilization of hospital services this part of the world.

Blood culture yields are known to be significantly lower among patients with pre-culture antibiotic use compared with those without antibiotic use [16]. This perhaps may have influenced the opinion of $26.4 \%$ of respondents who would not request for blood culture when indicated if the patients are already on antibiotics. The implication is that the few cases of BSI that would have yielded positive 
blood culture are missed and may not be properly treated, especially in this part of the world where most of our patients have taken some antibiotics before presenting to the hospital.

\section{REFERENCES}

1. Edmond MB, Wallace SE, McClish DK, Pfaller MA, Jones RN, Wenzel RP. Nosocomial bloodstream infections in United States hospitals: a three-year analysis. Clin Infect Dis. 1999; 29: 239-244.

2. Bates DW, Goldman L, Lee TH. Contaminant blood cultures and resource utilization: the true consequences of false-positive results. JAMA. 1991; 265: 365-69.

3. Norberg A, Christopher NC, Ramundo ML, Bower JR, Berman SA. Contamination rates of blood cultures obtained by dedicated phlebotomy vs intravenous catheter. JAMA 2003; 289: 726-729.

4. Strand CL, Wajsbort RR, Sturmann K. Effect of iodophor vs iodine tincture skin preparation on blood culture contamination rate. JAMA 1993; 269: 1004-1006.

5. Weinbaum FI, Lavie S, Danek M, Sixsmith D, Heinrich GF, Mills SS. Doing it right the first time: quality improvement and the contaminant blood culture. J. Clin. Microbiol. 1997; 35: 563-565.

6. Archer, G. L. Coagulase-negative staphylococci in blood cultures: the clinician's dilemma. Infect. Control.1985; 6: 477-478.

7. Parada JP, Schwartz DN, Schiff GD, Weiss KB. Effects of type and level of training on variation in physician knowledge in the use and acquisition of blood cultures: a cross sectional survey. BMC Infect Dis. 2005; 5: 71.

\section{CONCLUSION}

Through this study areas of unsatisfactory knowledge, attitude and practice of blood culture were identified. This will help in designing an educational intervention programme for the purpose of addressing identified problems areas in blood culture.

8. Weinstein MP. Current blood culture methods and systems: clinical concepts, technology, and interpretation of results. Clin Infect Dis. 1996; 23: 406.

9. Smith-Elekes S, Weinstein MP. Blood cultures. Inf Dis Clin North Am.1993; 7: 221-34.

10. Mazzuca SA, Cohen SJ, Clark CM Jr. Evaluating clinical knowledge across years of medical training. J Med Ed.1981; 56: 83-90.

11. Li J, Plorde JJ, Carlson LG. Effects of volume and periodicity on blood cultures. J Clin Microbiol.1994; 32: 2829-2831.

12. Mermel LA, Maki DG. Detection of bacteraemia in adults: consequences of culturing an inadequate volume of blood. Ann Intern Med.1993; 119: 270-272. 13. Connell TG, Rele M, Cowley D, Buttery JP, Curtis N. How reliable is a negative blood culture result? Volume of blood submitted for culture in routine practice in a children's hospital. Paediatrics.2007; 119: 891-896. 